\title{
Gene therapy for optic nerve disease
}

KRG Martin ${ }^{1,2}$ and HA Quigley ${ }^{2}$

Gene therapy as a therapeutic approach

Purpose There has been recent interest in the potential use of gene therapy techniques to treat ocular disease. In this article, we consider the optic nerve diseases that are potentially most amenable to gene therapy.

Methods We discuss the recent success of gene transfer experiments in animal models of glaucoma, optic neuritis, Leber's hereditary optic neuropathy (LHON), and optic nerve transection, and we assess the possibility of using similar techniques to treat human disease in the future.

Results We have achieved highly efficient transfection of retinal ganglion cells in a rat model of glaucoma following a single intravitreal injection of adeno-associated virus (AAV). In our model, we have found that AAV-mediated gene therapy with brainderived neurotrophic factor has a significant neuroprotective effect compared to saline or control virus injections. Guy and coworkers have successfully used AAV-mediated gene therapy to replace the defective mitochondrial enzyme subunit in cells derived from human patients with LHON. Gene therapy techniques have also shown promise in animal models of optic neuritis and optic nerve trauma.

Conclusions Human diseases with singlegene defects such as LHON may soon be treated successfully by gene therapy, assuming that vectors continue to improve and are well tolerated in the human eye. Other optic nerve diseases such as glaucoma that do not have a single-gene defect may also benefit from gene therapy to enhance RGC survival. In all cases, the risks of treatment will need to be balanced against the potential benefits.

Eye (2004) 18, 1049-1055.

doi:10.1038/sj.eye.6701579

Keywords: gene therapy; optic nerve; brainderived neurotrophic factor; adeno-associated virus; glaucoma
The possibility of using gene therapy as a treatment for human disease has received much recent attention. There are now a wide variety of vectors available that can mediate gene transfer to most tissues of the body, yet to date the success of these techniques in human patients has been limited. There are a number of reasons for the relatively poor results in human clinical trials to date. Firstly, many of the vectors used in early human studies caused significant side effects and were not well tolerated by patients. In cystic fibrosis patients, for example, the adenoviral vectors used in clinical trials begun in the early 1990s caused significant pulmonary inflammation. ${ }^{1,2}$ Secondly, the proportion of cells transfected and the duration for which transgene expression was maintained has tended to be very variable. Since the cloning of the cystic fibrosis gene (CFTR) in 1989, over 20 clinical trials of gene therapy have been carried out. Most trials demonstrated gene transfer to the airway, but gene transfer efficiency achieved with each of the three gene transfer agents used (adenovirus, adeno-associated virus and cationic liposomes) was low, and no significant clinical benefits were achieved. ${ }^{3}$ Thirdly, the risk of vector-induced mutagenesis has caused significant worries. Cavazzana-Calvo et $a l^{4}$ used a retroviral gene-therapy approach to treat infants born with X-linked severe combined immune deficiency (SCID). They achieved significant levels of immune reconstitution in all but one of the subjects, ${ }^{5}$ but the trial had to be suspended when two patients developed leukaemia. ${ }^{6,7}$ Concern about the risk of 'insertional oncogenesis' has led to the suspension of other human gene therapy trials using similar vectors to allow for further analysis of the risk-to-benefit ratio.

So, are there situations where gene therapy is likely to enter routine clinical practice?

Certainly, the problems and limitations of currently available techniques should not be underestimated, but there are reasons to believe that the future is still relatively bright for this

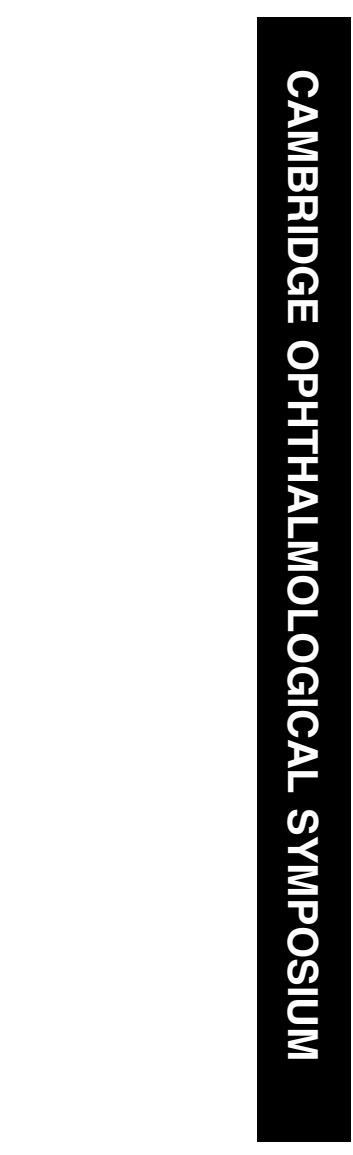

${ }^{1}$ Eye Department Addenbrookes Hospital Cambridge, UK

${ }^{2}$ Wilmer Eye Institute Johns Hopkins University Baltimore, USA

Correspondence: KRG Martin MA MRCP FRCOphth Eye Department Box 41 Addenbrookes Hospital Cambridge CB2 2QQ, UK Tel: + 441223245151 Fax: + 441223217968 E-mail: kmartin1@ doctors.org.uk

Received: 4 September 2003

Accepted: 4 September 2003

Conflicting interests: None.

Financial support: The TFC Frost Trust, University College Oxford, NEI EY02120. 
promising treatment modality. Safer vectors are being developed that are capable of long-term transgene expression in host cells. Understanding of the mechanisms by which vectors mediate integration of genes into the host geneome is also improving, with the aim of developing vectors with reduced risk of insertional mutagenesis. The mechanisms of transgene expression are also becoming clearer, and systems are under development to allow greater control of which host cells are transfected and how efficiently foreign genes are then expressed. The use of conditional promoters, for example, can allow the translation of foreign proteins to be effectively switched on or off by a chosen signal. In the case of tetracycline-inducible promoters, the signal is either the introduction or the withdrawal of a particular antibiotic. ${ }^{89}$ Such technologies allow more control over the whole process of gene therapy, but what is the potential application to the treatment of ocular disease in general and optic nerve diseases in particular?

\section{Gene therapy and the eye}

Compared to most other tissues of the body, the eye has several advantages that makes it a good candidate for gene therapy. The eye is a small organ, making the transfection of a significant proportion of the cells of interest a realistic possibility. In addition, the eye is relatively isolated, minimising the risk of unwanted transfection of other tissues remote from the site of disease. Also, most target cells for ocular gene therapy are not undergoing cell division, potentially reducing the risk of oncogenesis.

\section{Vectors for optic nerve gene therapy}

Currently, the most effective gene therapy vectors are viruses. Early ocular gene therapy experiments used adenoviral vectors, but these were limited by the severity of the inflammatory reaction induced and the relatively short duration for which transgenes could be expressed. Recombinant adeno-associated virus (AAV) vectors have proved to be extremely useful for ocular gene therapy. $\mathrm{AAV}$ is a small, double-stranded DNA virus that causes no known human disease. The recombinant form of AAV, commonly used for gene therapy experiments, is rep deficient meaning that it cannot replicate within the host cell. AAV vectors can be used to transfect a variety of ocular cell types including photoreceptors, ${ }^{10-12}$ retinal pigment epithelial cells,,$^{10,13,14}$ Muller cells, ${ }^{15}$ and retinal ganglion cells (RGC). ${ }^{16,17}$ Little ocular inflammation is induced and expression in RGC can persist for at least 1 year, raising hopes that AAV could be useful in the treatment of human optic nerve disease. ${ }^{17}$ We have recently reviewed our techniques for the highly efficient transduction of rat RGC using $\mathrm{AAV}^{18} \mathrm{~A}$ number of factors can improve the efficiency of AAV-mediated gene transfer to RGC. It is essential that high titres of viable virus are delivered to the eye. Effective RGC transfection also requires $\mathrm{AAV}$ to be administered intravitreally - very few ganglion cells are transduced following subretinal AAV injection. The choice of promoter sequence to drive transgene expression is also important, with cytomegalovirus/chicken beta actin hybrid promoters working particularly well in RGC. ${ }^{18}$ Finally, the translation of transfecting cDNA within host RGC can be enhanced dramatically by the incorporation of the woodchuck hepatitis posttranscriptional regulatory element (WPRE). Using these techniques, we have been able to achieve very high transfection efficiencies of cells in the RGC layer of the rat retina following a single intravitreal injection. ${ }^{19}$ (Figures 1 and 2). AAV vectors do have limitations, however. Of particular concern is the theoretical risk of insertional oncogenesis, as the recombinant form of the virus mediates random incorporation of transgenes into the host chromosomes. ${ }^{20}$ Also, the usefulness of AAV as a vector is limited by the relatively small amount of passenger DNA that can be incorporated. Although genes up to $6.0 \mathrm{~kb}$ have been packaged into $\mathrm{AAV}$, these oversized viruses were not infectious, ${ }^{21}$ and the usual packaging limit for AAV appears to be $5.1-5.3 \mathrm{~kb} .{ }^{21,22}$

Other viruses such as lentivirus and less immunogenic forms of recombinant adenovirus are also currently being investigated as potential ocular gene therapy vectors.

\section{Therapeutic approaches in optic nerve disease}

There are two main approaches by which gene therapy might be useful in the treatment of optic nerve diseases. Firstly, gene therapy could be used to correct a specific gene defect in conditions where the defect is well understood. Secondly, gene therapy could be used to alter host gene expression in a way that either slows the course of a disease or provides some form of protection from the consequences of the disease. To date, the 'defective gene replacement' method of gene therapy has been attempted mainly in models of photoreceptor and retinal pigment epithelial disease caused by mutations in a single gene. Correction of a specific ocular genetic defect requires gene delivery directly to the defective cells and has been successfully used to slow photoreceptor loss in rodent models of primary photoreceptor disease. ${ }^{12,23-25}$ As an example, AAV vectors have recently been used to restore photoreceptor structure and function in retinal degeneration slow $(r d s)$ mice. ${ }^{26}$ These mice have a mutation in the Prph 2 gene and mutations in this gene have also been demonstrated in 

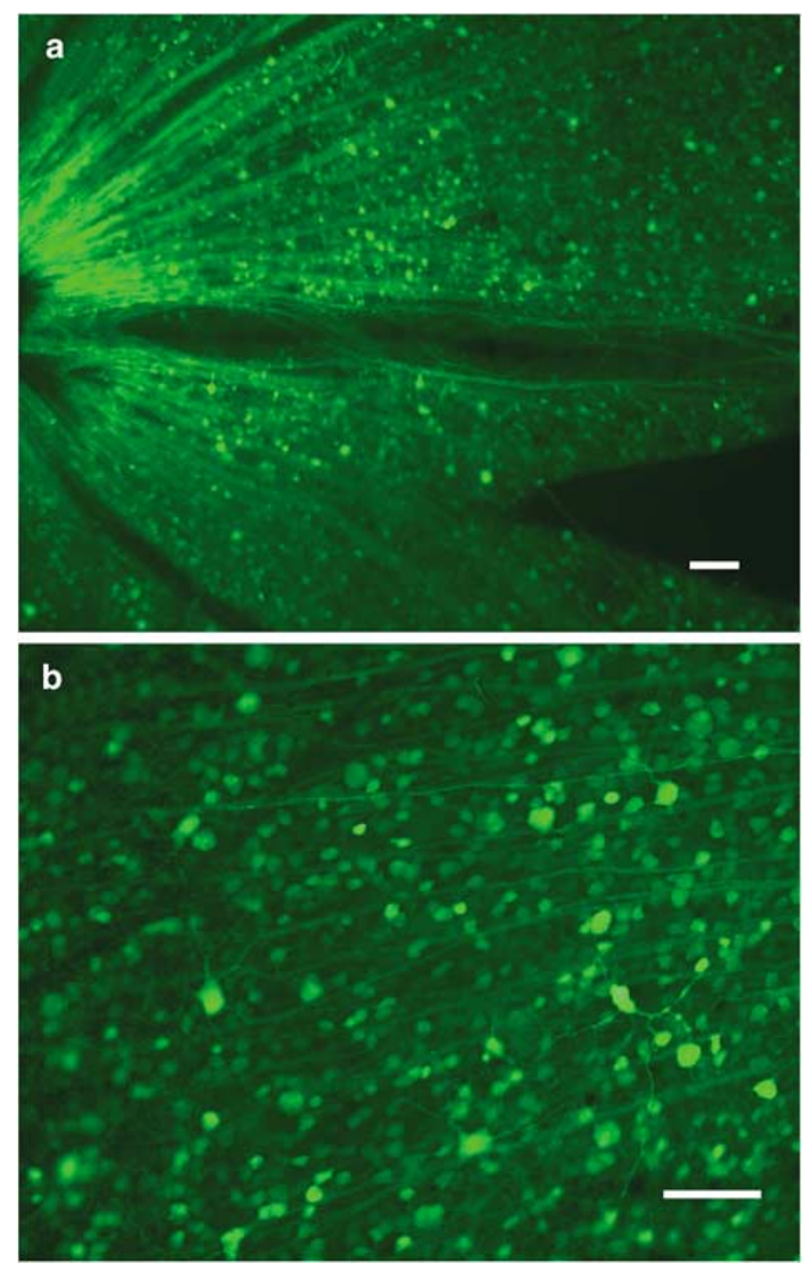

Figure 1 Retinal transfection by AAV-BDNF-WPRE. Highly efficient transduction of rat retinal ganglion cells with GFP 2 weeks after intravitreal administration of $2 \mu \mathrm{l} \mathrm{AAV-CBA-GFP-}$ WPRE at a concentration of $2 \times 10^{12}$ particles $/ \mathrm{ml}$. Representative retinal whole mounts as visualized by fluorescence microscopy using a GFP filter set are shown. GFP expression was extensive and almost confluent throughout the whole retina (a) in all replicate retinas examined $(n=13)$ with numerous RGC axons clearly visible (b). Scale bars $=100 \mu \mathrm{m}$.

human retinitis pigmentosa. $R d s$ mice injected subretinally with AAV-Prph2 developed new outer segment structures that contain rhodopsin and look ultrastructurally similar to normal rod photoreceptor outer segments. AAV-mediated gene replacement has also been used to restore visual function in a dog model of Leber's congenital amaurosis (LCA), a retinal degeneration that can cause severe childhood visual loss. ${ }^{27}$ The gene defect in the naturally ocurring dog model, a mutation in the RPE65 gene which codes for an RPE cell membrane-associated protein involved in retinoid metabolism, also occurs in human LCA. An AAV carrying wild-type RPE65 was able to restore vision as assessed by electroretinography, pupillometry, and psychophysical and behavioral tests. Human clinical trials using a similar vector are currently being planned.

But are there diseases of the optic nerve that might be open to a similar approach?

\section{Optic nerve diseases potentially treatable by gene therapy}

Leber's hereditary optic neuropathy

An example of a 'single gene defect' causing optic nerve disease is Leber's hereditary optic neuropathy (LHON). LHON is the most common of all inherited mitochondrial diseases. ${ }^{28}$ The disorder primarily affects men in the second or third decade of life, causing rapid painless visual loss in one eye followed weeks or months later by vision loss in the other eye. LHON is caused by mutations in mitochondrial DNA in a region coding for nicotinamide adenine

dinucleotide: ubiquinone oxidoreductase (complex I), an important enzyme involved in the oxidative

phosphorylation pathway. Three mitochondrial DNA mutations affecting different subunits of this enzyme account for $95 \%$ of LHON cases, with the G11778A mutation responsible for over $50 \%$ of cases. ${ }^{28}$ Recently, Guy et $a l^{29}$ have successfully used AAV-mediated gene therapy to replace the defective mitochondrial enzyme subunit in cells derived from human patients with LHON. ${ }^{29}$ Viral vectors cannot transfer genes directly to mammalian mitochondria, so a different approach was necessary to replace the defective mitochondrial protein. An AAV vector was used to transfer the nuclear-encoded version of the abnormal mitochondrial gene to the host cell cytoplasm. The cytoplasmically expressed protein was modified to include a mitochondrial targeting peptide to direct proper trafficking of the protein from the cytoplasm to the mitochondria.

Using this method, rescue of the mitochondrial oxidative phosphorylation deficiency seen in LHON was achieved in vitro. But could such techniques ever be justified in human LHON, assuming that the inherent technical difficulties could be overcome? Treating all those carrying the most common mutation might perhaps be one option, but as only $50 \%$ of male and $10 \%$ of female patients carrying the G11778A LHON mutation actually develop visual loss, this would be likely to involve significant risk to healthy eyes. ${ }^{30}$ It is also possible that injecting the virus after the visual loss has developed might be too late, especially as there is a lag of several weeks before optimal AAV-mediated transgene expression. Given the high risk of bilateral visual loss in LHON, perhaps the most realistic first approach in humans might be to treat the fellow eye after the visual loss has occured in the first eye. However, such intervention is still some way off, and the promising 

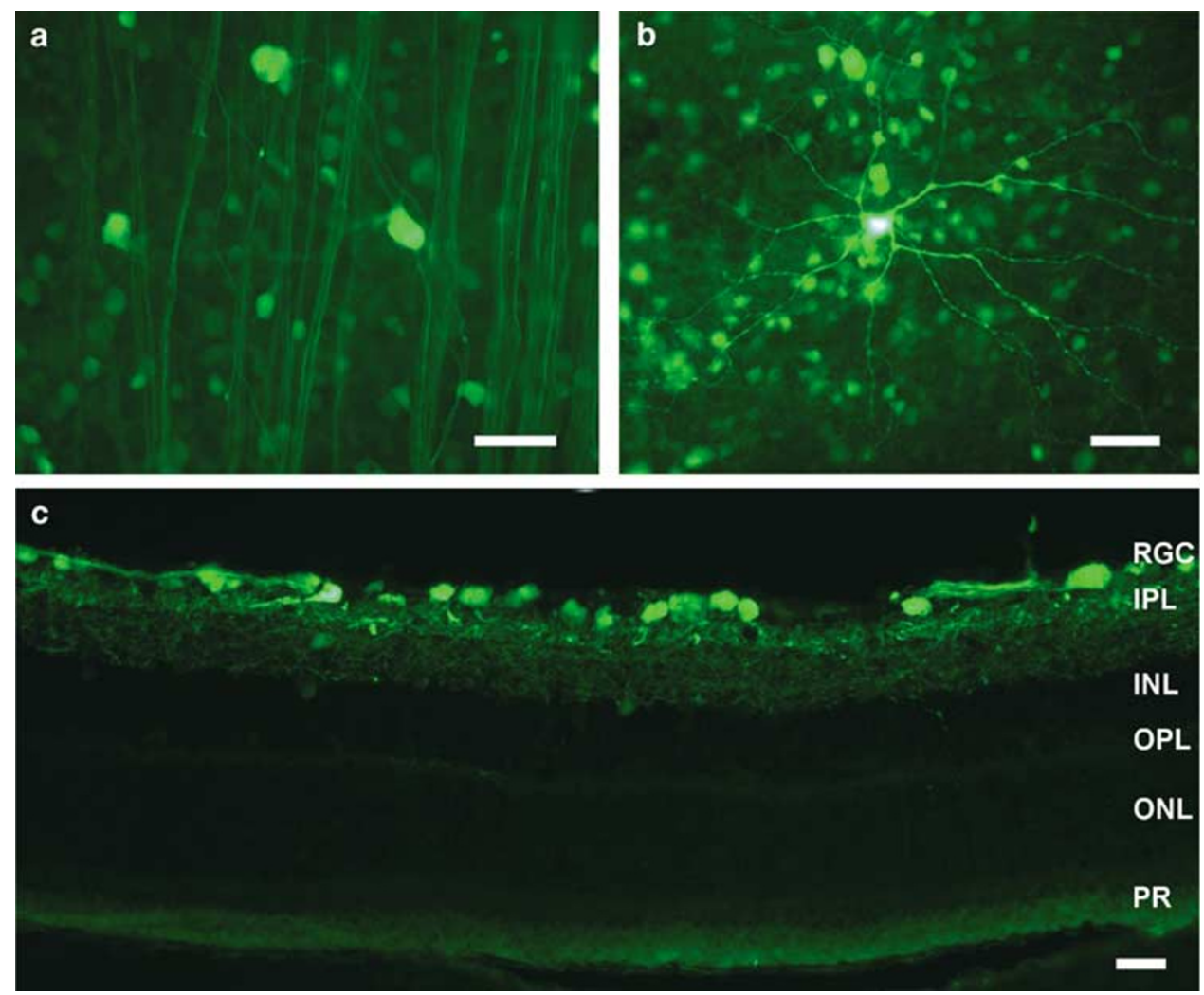

Figure 2 Retinal transfection by AAV-BDNF-WPRE. Transfection of the rat retina with AAV-CBA-GFP-WPRE allowed individual RGC and their axons to be seen clearly (a). The entire dendritic tree of a subset of RGC was also visualised (b). In retinal cross-sections ( $n=7$ eyes), GFP labelled cells were localised almost exclusively to the RGC layer (c). Scale bars $=50 \mu \mathrm{m}$.

results obtained in vitro will need to be confirmed in animal models before human studies can be contemplated.

For many optic nerve diseases no specific genetic defect has been characterised. It is likely that many of these diseases will turn out to be pathologically more complex than a well-characterised mutation in a single gene. In such situations, and in the context of injuries to optic nerve, the aim of gene therapy is to alter host gene expression in a manner that reduces the effect of the disease process.

\section{Glaucoma}

Glaucoma, the second leading cause of blindness in the world ${ }^{31}$ is an example of an ocular disease that is likely to involve the interaction of multiple genetic and

environmental factors, and as such is unlikely to be cured by the replacement of a single gene. The goal of gene therapy in glaucoma, therefore, is to slow the rate of RGC death. In order to reduce glaucomatous RGC loss using gene therapy techniques, suitable neuroprotective agents must first be identified. There are a number of strands of evidence that suggest brain-dervied neurotrophic factor (BDNF) as a potential neuroprotective agent in glaucoma. RGC are trophically dependent on BDNF, retrogradely transported from target areas in the brain to ganglion cell bodies in the retina, both during development and in adult life. ${ }^{32-34}$ There is evidence that when intraocular pressure is elevated, BDNF and its receptor trkB accumulate at the optic nerve head, suggesting that BDNF deprivation might be involved in glaucomatous RGC death. ${ }^{35}$ Furthermore, replacing BDNF by intravitreal injection in animal models of glaucoma has been shown to have a transient protective effect. ${ }^{36,37} \mathrm{As}$ frequent multiple intravitreal injections are unlikely to be a justifiable treatment for human glaucoma, gene therapy may represent a more viable approach. We used an AAV incorporating CDNA for BDNF to transfect RGC in a rat model of glaucoma. In our studies, a high proportion of RGC were transfected after a single intravitreal injection. After 4 weeks of experimental glaucoma, eyes that received intravitreal AAV-BDNF lost $32 \%$ of their RGC, compared to the $52 \%$ loss of RGC observed in eyes that received either a control AAV without BDNF or intravitreal saline. ${ }^{38}$ This corresponded to a $38 \%$ rescue of RGC by the AAV-BDNF virus, an effect that was highly statistically significant. Further work is underway to determine the duration of the protective effect, although other studies have shown that AAV 
can mediate transgene expression in RGC for at least one year. $^{17}$

Another approach to gene therapy in glaucoma has recently been reported by McKinnon and co-workers. They have taken a different approach, involving the modulation of pathways responsible for apoptosis in RGC. The final common pathway of RGC apoptosis involves the activation of caspase enzymes that participate in the mechanisms of cell suicide. McKinnon et al ${ }^{39}$ injected an AAV vector coding for human baculoviral IAP repeat-containing protein-4 (BIRC4), a potent caspase inhibitor, into one eye of rats. Experimental glaucoma was induced by sclerosis of aqueous humor outflow channels and the transgeneexpressing eyes had significantly greater RGC survival than control glaucoma eyes. BIRC4 promoted RGC survival, presumably by inhibiting the enzymatic completion of apoptosis, although there were differences in IOP exposure among treatment groups that were significant.

So, is gene therapy really a potentially useful treatment in glaucoma? Although IOP lowering is likely to remain the most useful intervention in glaucoma treatment, there is good evidence that some patients continue to get worse, even when low IOP is maintained. ${ }^{40-42}$ A small proportion of glaucoma patients progress to blindness at very low eye pressures. In these circumstances, there are no currently available treatments proven to reduce the risk of visual loss. Such patients would therefore be potentially good candidates for novel therapeutic approaches. The ideal neuroprotectant or combination of neuroprotectants to be delivered by gene therapy remains to be established. So far, most studies of gene therapy for glaucoma have been in rodents, and so further proof of principle is required in the eyes of larger animals before human trials can be contemplated. If the benefits of gene therapy for glaucoma are confirmed in larger eyes, the possibility of using similar techniques in humans will undoubtedly arise. As with all new treatments, the decision to treat must be based on a full analysis of the risks as well as the potential benefits. Although the risk of insertional oncogenesis is extremely low with AAV compared to retroviruses, this complication is still a theoretical possibility. Also, glaucoma is a chronic condition and it is thus likely that prolonged transgene expression will be required, ideally over a period of years. Although AAV can drive expression of transgenes in RGC for up to a year, ${ }^{17}$ the amount of protein expressed falls off with time. Other currently available vectors have similar or greater limitations. Given current technology, therefore, glaucoma patients might require multiple virus injections over their lifetime. Such a treatment approach might be justifiable in the absence of any effective alternative. Multiple intraocular injections are far from ideal, but it should be noted that such treatment is currently used for other serious ocular conditions such as viral retinitis. It is currently unknown if multiple injections of a vector will have a sustained effect or whether the benefits will only be maintained for a short duration. The possibility of an immune response to the vector at the second and subsequent injection has been raised, although evidence suggests this may not be too much of a problem with AAV. ${ }^{43}$ Ultimately, in carefully selected patients, gene therapy may well be a useful additional treatment, but there is still much work to do.

\section{Optic neuritis}

Gene therapy techniques have also been applied to experimental models of optic neuritis. ${ }^{44}$ Experimental allergic encephalomyelitis (EAE) is a widely used animal model of human multiple sclerosis. In the model, as in multiple sclerosis, myelin-producing oligodendrocytes of the optic nerve are a primary target of immune-mediated damage. Reactive oxygen species contribute to oligodendrocyte damage in EAE, and free-radical scavengers such as catalase have been shown to reduce optic nerve demelination and blood-brain barrier disruption in this model. However, the effectiveness of exogenously delivered catalase is limited because once the blood-brain barrier is re-established, the large catalase enzyme is unable to reach oligodendrocytes. Delivery of catalase to the optic nerve by gene therapy was therefore attempted to establish if prolonged delivery of catalase to the immediate vicinity of optic nerve oligodendrocyes could have an additional protective effect. ${ }^{44}$ Intravitreal injection of an AAV vector containing cDNA for catalase was performed in mice with EAE. After 1 month, cellspecific catalase activity assessed by immunolabelling was approximately doubled in endothelia, oligodendroglia, astrocytes, and optic nerve axons of AAV-catalase eyes compared to eyes injected with a control virus. The analysis of total remaining optic nerve myelin showed that catalase gene inoculation reduced demyelination by $38 \%$. The authors proposed that catalase gene delivery by using viral vectors could be a potential therapeutic strategy for the suppression of demyelination in multiple sclerosis. The visual function usually recovers after a single episode of optic neuritis, but multiple episodes can cause severe visual loss. Thus, gene therapeutic approaches might theoretically provide some benefit in patients with severe progressive optic nerve demyelination in the future, although this remains to be proven.

\section{Optic nerve trauma}

Injuries to the optic nerve are a rare but important cause of visual loss. Several animal models of optic nerve injury have been developed in which it is possible to 
study potentially neuroprotective gene therapy techniques. Optic nerve transection models are widely used, although they have the disadvantage that all RGC whose axons are transected will eventually die, and therefore any potential rescue effect will always be transient. Despite this limitation, recent studies have demonstrated an impressive protective effect of gene therapy in slowing RGC loss after axotomy. Cheng et $a l^{45}$ used AAV-mediated transfer of the gene for TrkB, a BDNF receptor, to rat RGC combined with exogenous BDNF administration. Their rationale was that, although exogenously administered BDNF slows RGC loss following optic nerve transection, the protective effect is very transient. In addition, neuronal injury is known to downregulate the expression of the Trk B receptor, ${ }^{46}$ potentially decreasing the effect of existing levels of BDNF. By using AAV-mediated gene transfer to increase the expression of the trkB receptor by RGC and then stimulating the receptors with intravitreally delivered BDNF, Cheng and co-workers reported markedly increased neuronal survival after optic nerve transection. In their experiments, $76 \%$ of RGC remained alive at 2 weeks after axotomy, a time when $>90 \%$ of these neurons are lost without treatment.

Significant slowing of RGC loss following optic nerve transection has also been achieved by adenoviral delivery of X-chromosome-linked inhibitor of apoptosis (Ad.XIAP) to the optic nerve stump. When this treatment was combined with intravitreal injection of an adenovirus encoding glial cell line-derived neurotrophic factor (Ad.GDNF), rescue of $47.3 \%$ of RGCs that would have undergone apoptosis 2 weeks after transection was achieved. ${ }^{47}$

Yet, when it comes to treating traumatised human optic nerves, a slight slowing of the rate of ganglion cell loss after injury is unlikely to be of significant benefit. What is needed is a treatment that can either prevent a significant proportion of injured cells from dying, or a treatment that can stimulate the regeneration of axotomised RGC. Neither of these goals have been achieved to date.

\section{Conclusions}

Although no gene therapy treatments have reached clinical use as yet for the treatment of human optic nerve diseases, there are some grounds for optimism that such treatments may find a role in the future. It certainly seems possible that single gene defects such as LHON could eventually be treated successfully by gene therapy, assuming that vectors continue to improve and are well tolerated in the human eye. Other optic nerve diseases without a single gene defect may also benefit from gene therapy to enhance RGC survival. In all cases, the risks of treatment will need to be balanced against the potential benefits. It is important to remember that in diseases such as glaucoma, it is not necessarily essential to stop RGC loss completely. If the processes of cell death can be slowed to the extent that the patient maintains useful vision for most if not all of their life, then that would still be a considerable advance.

\section{References}

1 Knowles MR, Hohneker KW, Zhou Z, Olsen JC, Noah TL, $\mathrm{Hu}$ PC et al. A controlled study of adenoviral-vectormediated gene transfer in the nasal epithelium of patients with cystic fibrosis. N Engl J Med 1995; 333(13): 823-831.

2 West J, Rodman DM. Gene therapy for pulmonary diseases. Chest 2001; 119(2): 613-617.

3 Griesenbach U, Ferrari S, Geddes DM, Alton EW. Gene therapy progress and prospects: cystic fibrosis. Gene Therapy 2002; 9(20): 1344-1350.

4 Cavazzana-Calvo M, Hacein-Bey S, de Saint Basile G, Gross F, Yvon E, Nusbaum P et al. Gene therapy of human severe combined immunodeficiency (SCID)-X1 disease. Science 2000; 288(5466): 669-672.

5 Hacein-Bey-Abina S, Le Deist F, Carlier F, Bouneaud C, Hue C, De Villartay JP et al. Sustained correction of X-linked severe combined immunodeficiency by ex vivo gene therapy. N Engl J Med 2002; 346(16): 1185-1193.

6 Hacein-Bey-Abina S, von Kalle C, Schmidt M, Le Deist F, Wulffraat N, McIntyre E et al. A serious adverse event after successful gene therapy for X-linked severe combined immunodeficiency. N Engl J Med 2003; 348(3): 255-256.

7 Kohn DB, Sadelain M, Glorioso JC. Occurrence of leukaemia following gene therapy of X-linked SCID. Nat Rev Cancer 2003; 3(7): 477-488.

8 Chtarto A, Bender HU, Hanemann CO, Kemp T, Lehtonen $\mathrm{E}$, Levivier $\mathrm{M}$ et al. Tetracycline-inducible transgene expression mediated by a single AAV vector. Gene Therapy 2003; 10(1): 84-94.

9 Kafri T, van Praag H, Gage FH, Verma IM. Lentiviral vectors: regulated gene expression. Mol Ther 2000; 1(6): 516-521.

10 Ali RR, Reichel MB, Thrasher AJ, Levinsky RJ, Kinnon C, Kanuga $\mathrm{N}$ et al. Gene transfer into the mouse retina mediated by an adeno-associated viral vector. Hum Mol Genet 1996; 5(5): 591-594.

11 Flannery JG, Zolotukhin S, Vaquero MI, LaVail MM, Muzyczka $\mathrm{N}$, Hauswirth WW. Efficient photoreceptor-targeted gene expression in vivo by recombinant adeno-associated virus. Proc Natl Acad Sci USA 1997; 94(13): 6916-6921.

12 Jomary C, Vincent KA, Grist J, Neal MJ, Jones SE. Rescue of photoreceptor function by AAV-mediated gene transfer in a mouse model of inherited retinal degeneration. Gene Therapy 1997; 4(7): 683-690.

13 Lai YK, Rakoczy P, Constable I, Rolling F. Adeno-associated virus-mediated gene transfer into human retinal pigment epithelium cells. Aust N Z J Ophthalmol 1998; 26(Suppl 1): S77-S79.

14 Grant CA, Ponnazhagan S, Wang XS, Srivastava A, Li T. Evaluation of recombinant adeno-associated virus as a gene transfer vector for the retina. Curr Eye Res 1997; 16(9): 949-956.

15 Liang FQ, Dejneka NS, Cohen DR, Krasnoperova NV, Lem J, Maguire AM et al. AAV-mediated delivery of ciliary neurotrophic factor prolongs photoreceptor survival in the rhodopsin knockout mouse. Mol Ther 2001; 3(2): 241-248. 
16 Ali RR, Reichel MB, De Alwis M, Kanuga N, Kinnon C, Levinsky RJ et al. Adeno-associated virus gene transfer to mouse retina. Hum Gene Ther 1998; 9(1): 81-86.

17 Guy J, Qi X, Muzyczka N, Hauswirth WW. Reporter expression persists 1 year after adeno-associated virusmediated gene transfer to the optic nerve. Arch Ophthalmol 1999; 117(7): 929-937.

18 Martin KR, Klein RL, Levkovitch-Verbin H, Valenta D, Baumrind LA, Pease ME et al. High efficiency transfection of rat retinal ganglion cells by a modified adeno-associated virus incorporating the woodchuck hepatitis posttranscriptional regulatory element. Invest Ophthalmol Vis Sci (ARVO Abstract) 2002.

19 Martin KR, Klein RL, Quigley HA. Gene delivery to the eye using adeno-associated viral vectors. Methods 2002; 28(2): 267-275.

20 Nakai H, Montini E, Fuess S, Storm TA, Grompe M, Kay MA. AAV serotype 2 vectors preferentially integrate into active genes in mice. Nat Genet 2003; 34(3): 297-302.

21 Dong JY, Fan PD, Frizzell RA. Quantitative analysis of the packaging capacity of recombinant adeno-associated virus. Hum Gene Ther 1996; 7(17): 2101-2112.

22 Hermonat PL, Quirk JG, Bishop BM, Han L. The packaging capacity of adeno-associated virus (AAV) and the potential for wild-type-plus AAV gene therapy vectors. FEBS Lett 1997; 407(1): 78-84.

23 Lau D, McGee LH, Zhou S, Rendahl KG, Manning WC, Escobedo JA et al. Retinal degeneration is slowed in transgenic rats by AAV-mediated delivery of FGF-2. Invest Ophthalmol Vis Sci 2000; 41(11): 3622-3633.

24 Liang FQ, Aleman TS, Dejneka NS, Dudus L, Fisher KJ, Maguire AM et al. Long-term protection of retinal structure but not function using RAAV.CNTF in animal models of retinitis pigmentosa. Mol Ther 2001; 4(5): 461-472.

25 Sarra GM, Stephens C, de Alwis M, Bainbridge JW, Smith $\mathrm{AJ}$, Thrasher AJ et al. Gene replacement therapy in the retinal degeneration slow (rds) mouse: the effect on retinal degeneration following partial transduction of the retina. Hum Mol Genet 2001; 10(21): 2353-2361.

26 Ali RR, Sarra GM, Stephens C, Alwis MD, Bainbridge JW, Munro PM et al. Restoration of photoreceptor ultrastructure and function in retinal degeneration slow mice by gene therapy. Nat Genet 2000; 25(3): 306-310.

27 Acland GM, Aguirre GD, Ray J, Zhang Q, Aleman TS, Cideciyan $\mathrm{AV}$ et al. Gene therapy restores vision in a canine model of childhood blindness. Nat Genet 2001; 28(1): 92-95.

28 Chinnery PF, Johnson MA, Wardell TM, Singh-Kler R, Hayes C, Brown DTet al. The epidemiology of pathogenic mitochondrial DNA mutations. Ann Neurol 2000; 48(2): 188-193.

29 Guy J, Qi X, Pallotti F, Schon EA, Manfredi G, Carelli V et al. Rescue of a mitochondrial deficiency causing Leber Hereditary Optic Neuropathy. Ann Neurol 2002; 52(5): 534-542.

30 Wallace DC, Singh G, Lott MT, Hodge JA, Schurr TG, Lezza $\mathrm{AM}$ et al. Mitochondrial DNA mutation associated with Leber's hereditary optic neuropathy. Science 1988; 242(4884): 1427-1430.

31 Quigley HA. Number of people with glaucoma worldwide. Br J Ophthalmol 1996; 80(5): 389-393.

32 Mansour-Robaey S, Clarke DB, Wang YC, Bray GM, Aguayo AJ. Effects of ocular injury and administration of brainderived neurotrophic factor on survival and regrowth of axotomized retinal ganglion cells. Proc Natl Acad Sci USA 1994; 91(5): 1632-1636.
33 Takano M, Horie H, Iijima Y, Dezawa M, Sawada H, Ishikawa Y. Brain-derived neurotrophic factor enhances neurite regeneration from retinal ganglion cells in aged human retina in vitro. Exp Eye Res 2002; 74(2): 319-323.

34 Watanabe M, Sawai H, Fukuda Y. Survival of axotomized retinal ganglion cells in adult mammals. Clin Neurosci 1997; 4(5): 233-239.

35 Pease ME, McKinnon SJ, Quigley HA, Kerrigan-Baumrind LA, Zack DJ. Obstructed axonal transport of BDNF and its receptor TrkB in experimental glaucoma. Invest Ophthalmol Vis Sci 2000; 41(3): 764-774.

36 Ko ML, Hu DN, Ritch R, Sharma SC, Chen CF. Patterns of retinal ganglion cell survival after brain-derived neurotrophic factor administration in hypertensive eyes of rats. Neurosci Lett 2001; 305(2): 139-142.

37 Ko ML, Hu DN, Ritch R, Sharma SC. The combined effect of brain-derived neurotrophic factor and a free radical scavenger in experimental glaucoma. Invest Ophthalmol Vis Sci 2000; 41(10): 2967-2971.

38 Martin K, Quigley H, DJZack, Levkovitch-Verbin H, Kielczewski J, Valenta D et al. Gene therapy with brainderived neurotrophic factors as a protection for retinal ganglion cells in a rat model of glaucoma. Invest Ophthalmol Vis Sci 2003 (in press).

39 McKinnon SJ, Lehman DM, Tahzib NG, Ransom NL, Reitsamer HA, Liston $\mathrm{P}$ et al. Baculoviral IAP repeatcontaining-4 protects optic nerve axons in a rat glaucoma model. Mol Ther 2002; 5(6): 780-787.

40 The Advanced Glaucoma Intervention Study (AGIS): 7. The relationship between control of intraocular pressure and visual field deterioration. The AGIS Investigators.. Am J Ophthalmol 2000; 130(4): 429-440.

41 Heijl A, Leske MC, Bengtsson B, Hyman L, Hussein M. Reduction of intraocular pressure and glaucoma progression: results from the Early Manifest Glaucoma Trial. Arch Ophthalmol 2002; 120(10): 1268-1279.

42 The Collaborative Normal-Tension Glaucoma Study Group. Comparison of glaucomatous progression between untreated patients with normal-tension glaucoma and patients with therapeutically reduced intraocular pressures. Collaborative Normal-Tension Glaucoma Study Group [see comments] [published erratum appears in Am J Ophthalmol 1999; 127(1):120]. Am J Ophthalmol 1998; 126(4): 487-497.

43 Anand V, Chirmule N, Fersh M, Maguire AM, Bennett J. Additional transduction events after subretinal readministration of recombinant adeno-associated virus. Hum Gene Ther 2000; 11(3): 449-457.

44 Guy J, Qi X, Wang H, Hauswirth WW. Adenoviral gene therapy with catalase suppresses experimental optic neuritis. Arch Ophthalmol 1999; 117(11): 1533-1539.

45 Cheng L, Sapieha P, Kittlerova P, Hauswirth WW, Di Polo A. TrkB gene transfer protects retinal ganglion cells from axotomy-induced death in vivo. J Neurosci 2002; 22(10): 3977-3986.

46 Shen S, Wiemelt AP, McMorris FA, Barres BA. Retinal ganglion cells lose trophic responsiveness after axotomy. Neuron 1999; 23(2): 285-295.

47 Straten G, Schmeer C, Kretz A, Gerhardt E, Kugler S, Schulz $\mathrm{JB}$ et al. Potential synergistic protection of retinal ganglion cells from axotomy-induced apoptosis by adenoviral administration of glial cell line-derived neurotrophic factor and X-chromosome-linked inhibitor of apoptosis. Neurobiol Dis 2002; 11(1): 123-133. 